\title{
A Proposal of The New Mechanism on Remnant Lipoprotein Formation and Clearance after Food Intake
}

Katsuyuki Nakajima* and Akira Tanaka

Laboratory of Clinical Nutrition and Medicine, Kagawa Nutrition University, Tokyo, Japan

"Corresponding author: Katsuyuki Nakajima, Laboratory of Clinical Nutrition and Medicine, Kagawa Nutrition University, Tokyo, Japan, Tel: 81-27-243-6390; Fax: + 81-27-243-6390; E-mail: nakajimak05@ybb.ne.jp

Received date: February 03, 2017; Accepted date: March 06, 2017; Published date: March 08, 2017

Copyright: () 2017 Nakajima K, et al. This is an open-access article distributed under the terms of the Creative Commons Attribution License, which permits unrestricted use, distribution, and reproduction in any medium, provided the original author and source are credited.

\begin{abstract}
To understand the mechanism of plasma TG increase after food intake, the characteristics of remnant lipoproteins in postprandial plasma and the role of lipoprotein lipase (LPL) were investigated. The accumulation of TG in remnant lipoproteins (RLP-TG) is caused by the unchanged levels of LPL activity for hydrolysis of chylomicrons and VLDL when overloaded at endothelium after food intake. This review proposed a new hypothesis on the metabolism of plasma TG-rich lipoprotein based on the no-change of LPL activity at endothelium after food intake and the discovery of RLP-LPL complex in postprandial plasma.
\end{abstract}

\section{Background}

The increase of plasma TG after food intake is one of the fundamental physiological phenomenon and postprandial hypertriglyceridemia has been considered as an important and emergent CVD risk factor. The mechanism of TG increase has been explained by the increase of fat absorption at intestine and its increased supply of chylomicrons into blood stream through lymphatic vessel. The contents of TG increased in plasma are explained as the increase of chylomicrons (CM), VLDL and their remnants (TG-rich lipoproteins) and cleared from the circulation mostly at liver through LRP-1 etc, [1]. However, the characteristics and the mechanism of TG and remnant lipoproteins increased in postprandial plasma have not been fully understood. Therefore, we have focused to investigate the characteristics of TG-rich lipoproteins in postprandial plasma and the role of lipoprotein lipase for the formation at endothelial cells and clearance of remnant lipoproteins in liver and muscle.

\section{Metabolic Pathway of CM, VLDL and Their Remnants After Food Intake}

Recent advances in our knowledge of CM assembly have focused on the roles of three key players in this process: apoB-48, microsomal triglyceride transfer protein (MTP), and apoA-IV at intestine and the formation of chylomicrons has been well established [2-5]. CM is secreted by the intestine after fat consumption. As shown Figure 1, CM particles contain apoB- 48 as a structural protein, which in humans is formed exclusively in the intestine after tissue-specific editing of the apoB-100 mRNA [6]. It appears that apoB-48 containing particles are continuously secreted from the enterocyte, and at times of excessive TG availability after fat consumption, lipid droplets fuse with nascent lipoprotein particles, resulting in the secretion of enormous CM [7]. Once the CM particle reaches the plasma compartment, apoA-I dissociates very rapidly [8] and acquires apoCs, in particular apoC-II, to enable efficient unloading of its massive TG content after binding to the LPL which is bound to the endothelium [9]. HDL is a major reservoir for the apoCs and apoE in conditions with low HDL concentrations (found most often in hypertriglyceridemic subjects). $\mathrm{CM}$ may receive apoCs and apoE from resident VLDL particles.

The CM particles are rapidly sequestered in the liver by binding to the heparan sulphate proteoglycan surface (HSPG) of hepatocytes [10]. This constitutes a high-capacity reservoir for adsorbing large amounts of CM in the postprandial state. Binding to HSPG is facilitated by apoE molecules present on the surface of the CM remnant particles. Once bound to the hepatocellular surface, the CM remnants are further enriched with apoE secreted by the hepatocytes. They are then internalized by two lipoprotein receptors: the low-density lipoprotein (LDL) receptor and the LDL receptor-related protein (LRP). Characterization of this distinct clearance pathway for CM remnants helps to direct further research towards developing an understanding of pathological abnormalities in postprandial lipoprotein metabolism.

Furthermore, a major proportion of CM remnants leave the plasma compartment quite rapidly while still quite large, i.e. $75 \mathrm{~nm}$ in diameter [11]. The half-life of CM-TG in healthy subjects is very short, approximately $5 \mathrm{~min}$ [12]. The half-life of CM particles has been very difficult to estimate due to the difficulty of obtaining adequate labeling of CM. The CM particle half-life is certainly longer than that of CMTG and seems to be quite heterogenous. Certain pools of $\mathrm{CM}$ remnants have a very long residence time, at least as long as similarsized VLDL particles [11,12]. There is competition for lipolysis: CM and VLDL mix in the blood and the two TRL species compete for the same lipolytic pathway [13]. It has been shown that endogenous TRL accumulate in human plasma after fat intake and the mechanism behind this phenomenon is explained by the delayed lipolysis of the apoB-100 TRL particles due to competition with CM for the sites of LPL action [13]. Similarly, endogenous TRL accumulate in rat plasma due to competition with a CM-like TG emulsion for the common lipolytic pathway [14]. The increase in the number of TRL apoB-100 particles is actually far greater than that of the apoB- 48 containing lipoproteins in the postprandial state [15]. Of note, the accumulation of large TRL apoB-100 particles seems to be a particular sign in hypertriglyceridemic patients with CAD compared with healthy hypertriglyceridemic subjects, suggesting a link between the 
Citation: Nakajima K, Tanaka A (2017) A Proposal of The New Mechanism on Remnant Lipoprotein Formation and Clearance after Food Intake.

Page 2 of 8

accumulation of large VLDL and the development of atherosclerosis [16].

VLDL particles are secreted continuously from the liver. In contrast to $\mathrm{CM}$ and their remnants, they are characterized by their apoB-100 content. The secretion of VLDL is under complex regulation, as the larger and more TG-rich VLDL species are under strict insulin control in a dual sense.

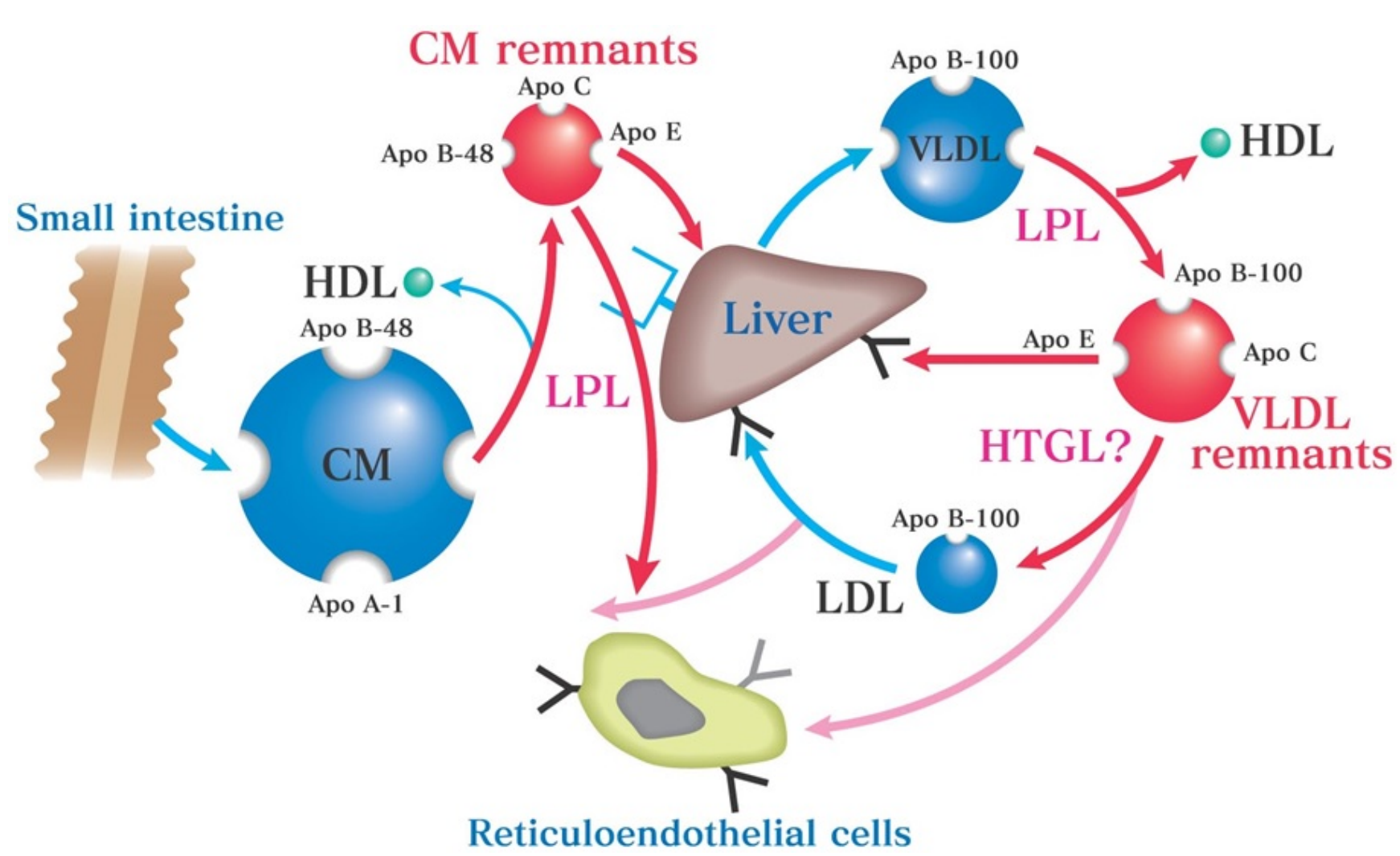

Figure 1: After fat intake, the intestine secretes CM, the TG of which are lipolyzed by LPL. The LPL reaction constitutes the initial process in the formation of TRL remnants. The VLDL secretion process is partly regulated by the rate of FFA influx to the liver. VLDL-TG are lipolyzed by endothelial-bound LPL, and VLDL remnant particles are formed. The final TRL remnant composition is modulated by the CETP reaction with HDL, HTGL, and the exchange of soluble apolipoproteins such as C-I, C-II, C-III and E. The great majority of the remnants are removed from plasma by receptor-mediated process, the principal receptors are the LDL receptor and the LDL-receptor-related protein (LRP). It is probable that the CM remnants use both of these routes, whereas the VLDL remnants are more likely to use only the LDL receptor.

First, a number of more or less insulin-sensitive mechanisms regulate the availability of TG for VLDL production. The free fatty acids (FFA) which are generated by lipolysis in adipose tissue through the action of hormone-sensitive lipase provide a major source for hepatic VLDL secretion. Insulin stimulates the endothelial expression of LPL, the key enzyme in TRL metabolism, in a post-transcriptional manner [17,18]. Hepatic uptake of poorly lipolyzed VLDL or CM remnant particles may also contribute to the hepatocellular TG availability. Similarly, reduced uptake of FFA in adipose and muscle tissues after LPL-mediated lipolysis of CM and VLDL shunts FFA to the liver [19]. Finally, the liver has the capacity of de novo synthesis of TG and VLDL.

\section{Definition of TG-Rich Lipoproteins and Remnant Lipoproteins}

The increase of TG-rich lipoproteins in plasma after food intake has been known as an essential physiological phenomenon associated with the formation of remnant lipoproteins [20]. However, the definition of remnant lipoproteins in plasma has been confused for many years because of the variety of methods used to determine its plasma concentration [21]. The most common definition of remnant lipoproteins proposed several decades ago has been the intermediate density lipoproteins (IDL) isolated by an ultracentrifugation method as other lipoprotein fractions [22]. Also the most important characteristics of remnant lipoproteins has been recognized as TG-rich lipoproteins which increase significantly after food intake $[1,23]$. However, IDL is known not to increase after food intake associated with TG increase. Therefore, IDL has become inconspicuous as a fraction of remnant lipoproteins [23,24]. There are other methods, such as electrophoresis, NMR and HPLC which are used to identify remnant lipoproteins by charge, particle size [21] and the calculation [25]. However, those methods can neither isolate a substantial remnant lipoproteins from plasma nor determine the TG levels in remnant lipoproteins specifically. 


\section{Isolation and Detection of Remnant Lipoproteins in Postprandial Plasma}

We established the isolation method of remnant lipoproteins in plasma by an immunoaffinity gel separation method since 1993 and investigated the characteristics and clinical significance of plasma remnant lipoproteins as RLP-cholesterol (RLP-C) and RLP-triglyceride (RLP-TG) [26,27]. RLP isolated by this method is identified as apoErich, apoC3-rich and cholesteryl-ester rich VLDL [26-31]. This lipoprotein fraction has shown high similarity with the definition of remnant lipoproteins previously reported by Havel et al. [1]

Using the isolation method of remnant lipoproteins, we determined the concentration of TG as RLP-TG in the postprandial plasma and compared with those in the fasting plasma. Significant differences were found between fasting and postprandial TG and RLP-TG concentration, RLP-TG/ TG and RLP-TG/RLP-C ratio (particle size) [32] during 6 hours after fat load (Table 1). The particle size of remnant lipoproteins became significantly large (more than 4-folds) among healthy volunteers in thours after fat load. In particular, the increase in the postprandial delta RLP-TG level (postprandial RLP-TG minus fasting RLP-TG) contributed to approximately $80-90 \%$ of the increase in the postprandial delta TG after fat load or fat rich meal (Figure 2) [33].
$2 \mathrm{~h}$ after fat load -Fasting Delta TG vs Delta RLP-TG

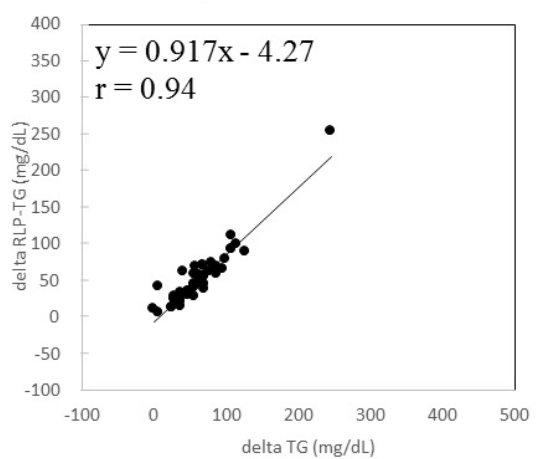

4h after fat load -Fasting Delta TG vs Delta RLP-TG

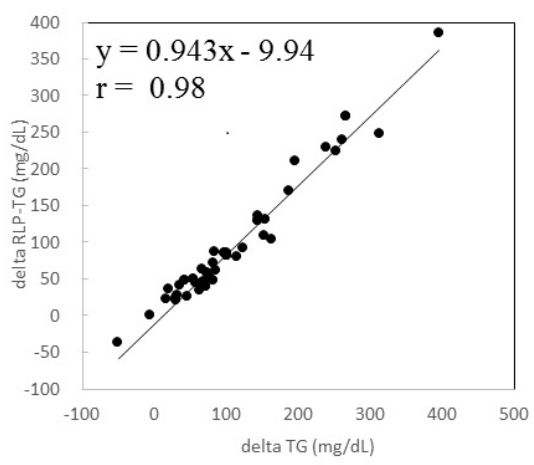

$6 \mathrm{~h}$ after Fat load -Fasting Delta TG vs Delta RLP-TG

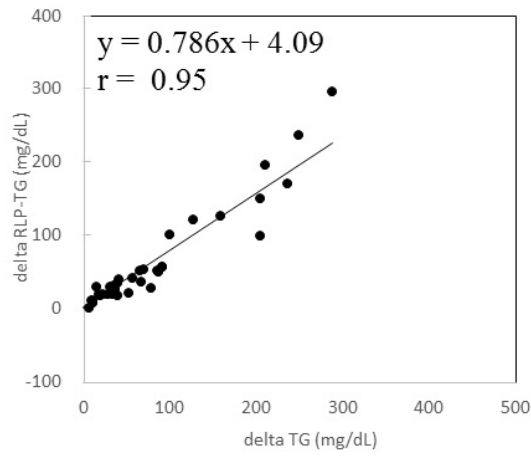

Figure 2: The correlation between plasma TG and RLP-TG concentration in the fasting and postprandial plasma. The changes of plasmadelta TG and delta RLP-TG concentration in $2 \mathrm{~h}, 4 \mathrm{~h}$, and $6 \mathrm{~h}$ after fat load. Delta TG and delta RLP-TG means that fasting TG and RLP-TG were subtracted from TG and RLP-TG after fat load.

However, approximately $50-60 \%$ of the increased delta TG was comprised of delta RLP-TG after typical moderate meal intake [34]. These results clearly show that the kind of foods as contained in a fat rich meal greatly enhance the formation of remnant lipoproteins in the postprandial plasma compared with a typical moderate meal.

\section{Discovery of RLP-LPL Complex in Plasma}

Using the immunoaffinity separation method of remnant lipoproteins, we found that the majority of LPL in plasma presented in RLP fraction which we isolated as remnant lipoproteins for many years [35].

The new findings are as follows. 1) More than $80 \%$ of circulating LPL in non-heparin plasma was found in RLP as RLP-LPL complex. 2) The circulating LPL found in RLP in the non- and post-heparin plasma was shown as LPL dimers but in the inactive form. 3) When lipolytic activity was inhibited by tetrahydrolipstatin (THL) in the post-heparin plasma, most LPL dimers were found in the VLDL elution range, specifically in the RLP. When the ex vivo lipolytic activity was not inhibited by THL, the LPL dimers became transitional in the postheparin plasma and shifted rapidly to the HDL elution range. 4) Two different type of LPL dimers were found in post-heparin plasma; one is active form found mostly in HDL elution range, the other is inactive form found in RLP. 5) The proposed model of the RLP-LPL complex shows that when LPL is detached from the endothelium surface, LPL is mostly released as the complex with RLP and inhibitors (apoC1, C3) with inactive form into the blood. Those results provided a new insight of LPL and remnant lipoprotein interaction in the circulating plasma. Therefore, we have proposed that the TG-rich lipoproteins bound to LPL dimers with inactive form is the new definition of remnant lipoproteins [35].

\section{Formation of Remnant Lipoproteins by LPL at Endothelium}

After the reduction in the TG content by LPL, CM and VLDL particles have been generally believed to become smaller remnant particles such as IDL. However, several studies, including our own [36-38] reported that remnant lipoproteins were predominantly of large VLDL size, which remained without further hydrolysis associated with less efficient LPL activity and concentration at endothelium. For many years, it has been believed that LPL activity in plasma increases significantly after food intake associated with the increase of TG-rich lipoproteins in order to metabolize the postprandial lipids of overloaded CM and VLDL more efficiently $[39,40]$, but we recently reported that LPL concentration in non-heparin plasma did not increase after food intake (Table 1 and Figure 3) [41]. 
Citation: Nakajima K, Tanaka A (2017) A Proposal of The New Mechanism on Remnant Lipoprotein Formation and Clearance after Food Intake.

\begin{tabular}{|c|c|c|c|c|}
\hline & $\mathrm{Oh}$ & $2 \mathrm{~h}$ & $4 \mathrm{~h}$ & $6 \mathrm{~h}$ \\
\hline & median ( $25 \%-75 \%$ tile) & median $(25 \%-75 \%$ tile) & median $(25 \%-75 \%$ tile) & median $(25 \%-75 \%$ tile) \\
\hline $\mathrm{TC}(\mathrm{mg} / \mathrm{dl})$ & $225(184-250)$ & $230(180-260)$ & $230(180-250)$ & $230(180-260)$ \\
\hline TG (mg/dl) & $113(66-160)$ & $140(110-220)^{\star}$ & $180(140-380)^{*}$ & $160(80-300)^{*}$ \\
\hline HDL-C (mg/dl) & $67(45-80)$ & $70(40-80)$ & $70(40-80)$ & $70(40-80)$ \\
\hline LDL-C (mg/dl) & $128(105-150)$ & $130(100-150)$ & $130(100-140)$ & $130(100-150)$ \\
\hline RLP-C (mg/dl) & $5.6(3.9-6.9)$ & $6.3(4.9-8.4)^{*}$ & $8.1(5.4-13.8)^{*}$ & $7.5(4.7-20)^{*}$ \\
\hline RLP-TG (mg/dl) & $13.8(5.5-29.3)$ & $37.7(15.4-68.4)^{*}$ & $86.2(38.4-224.4)^{*}$ & $77.7(16.3-142.4)^{\star}$ \\
\hline RLP-TG/RLP-C & $2.1(1.3-4.9)$ & $7.2(5.7-8.5)^{\star}$ & $11.6(6.4-15.9)^{\star}$ & $5.6(3.4-11.4)^{*}$ \\
\hline RLP-TG/TG & $0.11(0.08-0.19)$ & $0.32(0.27-0.34)^{\star}$ & $0.47(0.31-0.59)^{*}$ & $0.36(0.19-0.55)^{\star}$ \\
\hline apo B100 (mg/dl) & $111.9(88.8-162.4)$ & $126.4(87.7-173)$ & $126.2(95-160.2)$ & $126.6(101-168.3)$ \\
\hline Apo B-48 ( $\mu \mathrm{g} / \mathrm{ml})$ & $6(3.1-10.3)$ & $10.8(6.3-14)^{*}$ & $13(6.4-18.3)^{*}$ & $9.3(3.8-22.8)^{*}$ \\
\hline LPL (ng/ml) & $71.1(58.2-77.1)$ & $69(56.4-84.0)$ & $61.8(54.0-69.0)$ & $66.6(50.7-77.7)$ \\
\hline LPL/RLP-TG & $5.15(2.63-10.58)$ & $1.83(1.22-3.66)^{\star}$ & $0.71(0.30-1.40)^{*}$ & $0.86(0.54-3.11)^{*}$ \\
\hline
\end{tabular}

Table 1: The changes of plasma lipids, lipoproteins and LPL concentration after fat load in healthy Japanese volunteers.

\begin{tabular}{|c|c|c|c|}
\hline & Fasting $(n=79)$ & Postprandial (n=79) & \\
\hline & median (25\%tile-75\%tile) & median (25\%tile-75\%tile) & $\mathrm{p}$ \\
\hline TC (mg/dl) & $160(141-182)$ & $160(145-184)$ & n.s. \\
\hline TG (mg/dl) & $47(31-74)$ & $73(44-106)$ & $p<0.001$ \\
\hline HDL-C (mg/dl) & $47(41-59)$ & $47(40-58)$ & n.s. \\
\hline LDL-C (mg/dl) & $90(70-107)$ & $91(73-108)$ & n.s. \\
\hline sd-LDL (mg/dl) & $21.4(16.9-31.0)$ & $24.4(18.7-36)$ & n.s. \\
\hline RLP-C (mg/dl) & $3.5(2.5-4.8)$ & $4.7(3.5-6.8)$ & $p<0.001$ \\
\hline RLP-TG (mg/dl) & $4.2(2.3-7.3)$ & $14.6(8.0-28.5)$ & $p<0.001$ \\
\hline RLP-TG/RLP-C & $1.4(0.7-2.0)$ & $3.6(1.9-5.3)$ & $p<0.001$ \\
\hline RLP-TG/TG & $0.09(0.06-0.11)$ & $0.23(0.15-0.30)$ & $p<0.001$ \\
\hline LPL (U/I) & $79(68.5-89.3)$ & $66(57.0-78.6)$ & $p<0.001$ \\
\hline LPL (ng/ml) & $206.4(176.9-250.9)$ & $205.5(175.7-237.8)$ & n.s. \\
\hline LPL (U/l)/RLP-TG & $19.6(10.4-34.0)$ & $4.4(2.2-8.9)$ & $p<0.001$ \\
\hline LPL (ng/ml)/RLP-TG & $56.5(26.9-98.5)$ & $12.5(7.2-28.0)$ & $p<0.001$ \\
\hline
\end{tabular}

Table 2: Characteristics of lipids, lipoproteins and lipases in the fasting and postprandial state in post-heparin plasma; Effect of standard meal assessments in American healthy volunteers.

Moreover, LPL activity after heparin injection in the postprandial plasma did not increase after food intake, rather slightly decreased compared with LPL activity in the fasting plasma (Table 2).
Therefore, we have concluded that LPL activity and concentration in plasma do not change after any kind of food intake, unlike previously reported. RLP-TG increase after food intake means not only an increase of TG concentration in remnant lipoprotein particles, but it reflected insufficient hydrolysis. 


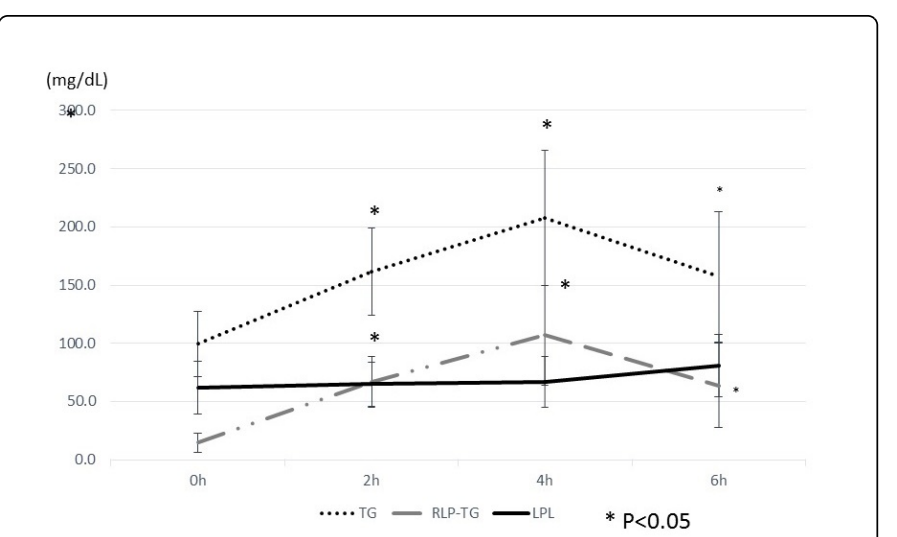

Figure 3: The changes of plasma TG, RLP-TG and LPL at $0 \mathrm{~h}, 2 \mathrm{~h}, 4 \mathrm{~h}$ and $6 \mathrm{~h}$ after fat load. TG and RLP-TG increased significantly after fat load associated with the increase of overloaded CM and VLDL in postprandial plasma, but LPL concentration did not increase after fat load in non-heparin plasma.

The increase of the particle size was shown by the increased RLPTG/RLP-C ratio after food intake [32]. A significant increase in the RLP-TG/RLP-C ratio was always found in the postprandial plasma after a fat load or typical moderate food intake in both normal subjects and CAD patients [34]. We previously reported that the particle size of remnant lipoproteins were inversely correlated with LPL activity and concentration [36]. Large RLP particles carry a significantly less LPL concentration per particle compared to small RLP particles, as shown by the LPL/RLP-TG ratio $[34,35,41]$. It is because unchanged concentration of LPL on the endothelium after food intake has to hydrolyze significantly increased CM and VLDL particles. Therefore, large size RLP particles are formed on the endothelium and released into the postprandial plasma carrying small amount of LPL. Recently, Buttet et al. [42] reported more comprehensive explanation on high levels of postprandial triglycerides associated with large particle size. They explained that it is based on the result of increased intestinal absorption/synthesis of triglycerides; i.e. in the setting of insulin resistance, CD36 is deregulated leading to MTP increased activity, a lower expression of apo CII, with the consequent increased chylomicron synthesis and high postprandial hypertriglyceridemia. Also Pérez-Méndez et al. [43] reported the different metabolism in LPL deficiency case that the heterozygous carriers of 2 different mutations in the LPL gene had different VLDL apo B FCR, and from normal to slightly low HDL apolipoprotein FCR and PR. These results disagree with the putative enhanced apo AI FCR in LPL deficient patients and suggested the need to reconsider the effects of LPL activity on postprandial lipoprotein metabolism. As complete LPL deficiency cases can't form remnants at endothelium as shown in Figure 4 and accumulates TG-rich lipoproteins (TRL; CM and VLDL) with significantly large particle size. Those cases don't increase postprandial atherogenic remnant lipoproteins, because of the lack of LPL activity.

Recently, Beigneux et al. [44] reported that GPIHBP1, a glycosylphosphatidylinositol (GPI)-anchored protein of capillary endothelial cells, is crucial for the lipolytic processing of triglyceriderich lipoproteins (TRLs). GPIHBP1 binds LPL in the interstitial spaces and shuttles LPL to its site of action in the capillary lumen. GPIHBP1 is also required for the margination of TRLs along capillaries-so that lipolytic processing can proceed. GPIHBP1 deficiency in humans causes severe hypertriglyceridemia (chylomicronemia).

When LPL activity is blocked by either genetic defects or auto antibodies against LPL and GPIHBPI, LPL can't form remnants of CM and VLDL at endothelium, which causes pancreatitis, but not atherosclerotic diseases. We have recently reported that the autoantibody against GPIHBP1 completely blocked LPL activity and induced severe hypertriglyceridemia without forming CM and VLDL remnants even after food intake [45].

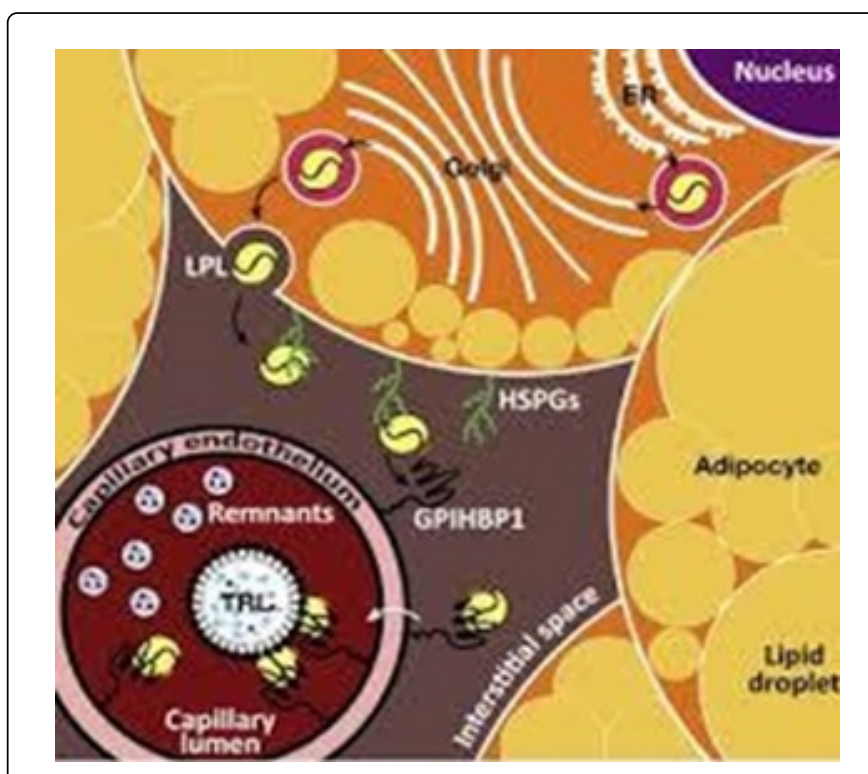

Figure 4: LPL is secreted from adipocytes and move to interstitial space. GPIHBP1, a glycosylphosphatidylinositol (GPI)-anchored protein of capillary endothelial cells, binds LPL in the interstitial spaces and shuttles LPL to its site of action in the capillary lumen. GPIHBP1 is also required for the margination of TRLs along capillaries-so that lipolytic processing can proceed. GPIHBP1 deficiency in humans causes severe hypertriglyceridemia (chylomicronemia), because of the lack of LPL activity. Without the presence of GPIHBP1, LPL can't form remnants of CM and VLDL at capillary endothelium, remaining as large lipoprotein particles which often cause pancreatitis.

\section{Role of LPL for the Clearance of Remnant Lipoproteins from The Circulation.}

Although the clearance of TG-rich lipoprotein from circulation has been extensively investigated with apoE phenotype such as apoE $2 / 2$ in type III [1] or apoE4/3 phenotype [46] associated with apoE receptor, we have paid more attention to LPL/RLP-TG ratio as a ligand of remnant clearance, because we experienced that apoE phenotype and the delay of clearance of TRL after fat load has not been well correlated except in type III cases [28].

When remnant lipoproteins are formed and detached from the endothelium, majority of those particles are released into the circulation as the RLP-LPL complex (Figure 5).

As LPL is bound to RLP in non-heparin plasma, LPL could be a ligand for remnant receptors in liver and muscle as inactive form $[47,48]$. In order to express the interaction correlation between TG 
content and LPL activity in RLP particles, we calculated the LPL/RLPTG ratio as Felts et al. proposed [49]. For example, when LPL bound to RLP increased significantly after heparin administration, RLP-TG decreased significantly as the result of LPL-RLP interaction [35]. Therefore, its interaction correlation was expressed as LPL/RLP-TG ratio or LPL/TG ratio (Table 1 : Fifty four Japanese volunteers for the oral fat load test who were without any CVD, diabetes or other distinctly evident diseases (30 males and 24 females, aged $28-63$ y, Table 2: Seventy nine relatively healthy young US volunteers (some were overweight or obese) in a male $(n=40)$ and female $(n=39)$ population (Caucasian 45, Asian 10, Hispanic 9, African American 7, others 8 ) with a median age of 24). As postprandial large RLP particles (high RLP-TG/RLP-C ratio) at $4 \mathrm{~h}$ after fat load showed approximately $1 / 4$ of LPL/RLP-TG ratio compared to fasting small RLP particles before fat load (Tables 1 and 2), the function of LPL as a ligand for the receptor binding may become less effective for the clearance from the circulation. Therefore, high TG with low LPL RLP particles in patients with diabetes and cardiovascular disease are obliged to the delayed clearance of RLP compared with that of healthy controls [50,51]. Typical peak time of RLP-TG or TG concentration after fat load in healthy controls are shown in 2-4 h, while delayed in 4-6 h in CAD patients [52,53], indicating the longer residing time of RLP in circulation in CAD patients.

As RLP is known to be cleared by LRP and VLDL receptors in liver and muscle, those interactions could be controlled by LPL concentration in RLP as a ligand to the receptors [36,54,55]. Beisiegel et al. reported that $\mathrm{CM}$ incorporation into HepG2 was increased according to the LPL concentration added, namely followed by the increase of ligand LPL to the remnant receptors [47]. Those results also suggest that the large RLP particles with small amount of LPL in the postprandial plasma is a higher risk factor for cardiovascular disease, as shown previous reports [56-58]. These results also support the previous studies that showed the non-fasting TG levels to be stronger predictor for the risk of CVD than fasting TG [59-61], because of the higher RLP-TG/TG ratio and the concentration of a larger sized RLP particles along with a small amount of LPL in the postprandial plasma compared to the fasting plasma. Therefore, non-fasting TG measurements together with LPL concentration performed 3-6 h after food intake may be able to take the place of the direct measurement of RLP-TG for the assessment of cardiovascular disease risk.

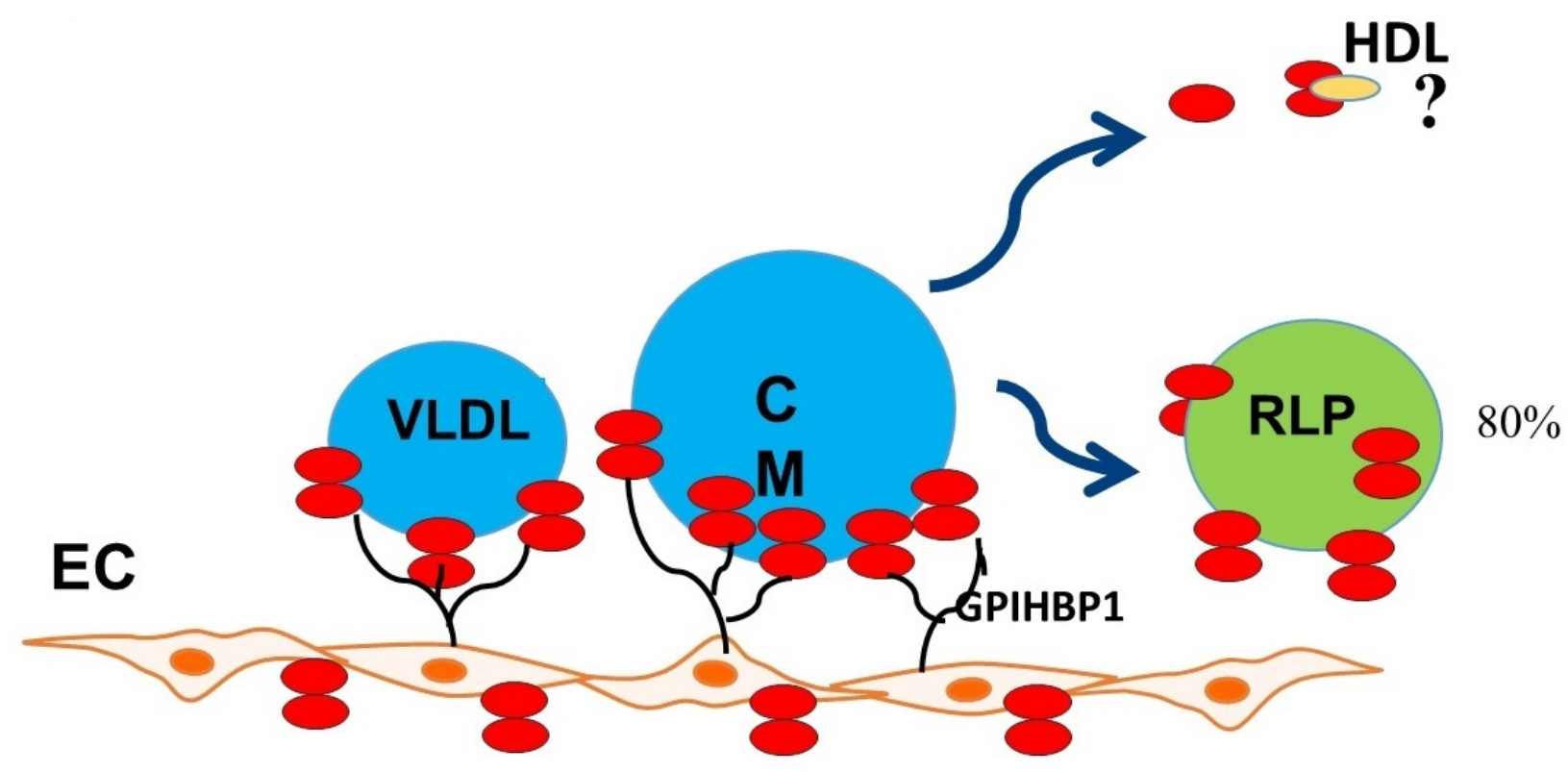

Figure 5: After the hydrolysis of CM and VLDL, most of the LPL is dissociated from endothelium into circulation as the RLP-LPL complex with dimeric but inactive form, possibly by the presence of inhibitors such as apoC1 and C3. A small amount (approximately 20\%) of LPL bound to non-RLP fraction (possibly an active form) were also found in pre-heparin plasma.

\section{Summary}

The present report clarified that the majority of LPL in non-heparin plasma was bound to RLP particles and LPL concentration doesn't increase after food intake associated with the increase of TG-rich lipoproteins. The amount of LPL on TG-rich lipoprotein particles reflect the particle size formation of remnant lipoproteins followed by the excessive supply of chylomicrons and VLDL after food intake. Large RLP particles carry less amount of LPL and less effectively cleared from the circulation because of the less ligand capacity. Therefore, we have proposed the new mechanism of remnant lipoprotein increase after food intake, based on the no increase of LPL at endothelium and the presence of RLP-LPL complex in circulation.

\section{References}

1. Havel RJ (1994) Postprandial hyperlipidemia and remnant lipoproteins. Curr Opin Lipidol 5: 102-109.

2. Black DD (2007) Development and physiological regulation of intestinal lipid absorption. I. Development of intestinal lipid absorption: cellular events in chylomicron assembly and secretion. Am J Physiol Gastrointest Liver Physiol 293: G519-G524. 
3. Tso P, Liu M (2004) Apolipoprotein A-IV, food intake, and obesity. Physiol Behav 83: 631-643.

4. Siddiqi SA, Siddiqi S, Mahan J, Peggs K, Gorelick FS, et al. (2006) The identification of a novel endoplasmic reticulum to Golgi SNARE complex used by the prechylomicron transport vesicle. J Biol Chem 281: 20974-20982.

5. Neeli I, Siddiqi SA, Siddiqi S, Mahan J, Lagakos WS, et al. (2007) Liver fatty acid-binding protein initiates budding of pre-chylomicron transport vesicles from intestinal endoplasmic reticulum. J Biol Chem 282 17974-17984.

6. Hayashi H, Fujimoto K, Cardelli JA, Nutting DF, Bergstedt S, et al. (1990) Fat feeding increases size, but not number of, chylomicrons produced by small intestine. Am J Physiol 259: 709- 719.

7. Martins IJ, Sainsbury AJ, Mamo JCL, Redgrave TG (1994) Lipid and apolipoprotein B48 transport in mesenteric lymph and the effect of hyperphagia on the clearance of chylomicron-like emulsions in insulindeficient rats. Diabetologia 37: 238- 246.

8. Vinge JL, Havel RJ (1981) Metabolism of apolipoprotein A-I of chylomicrons in rats and humans. Can J Biochem 59: 613-619.

9. Patsch J (1987) Postprandial lipaemia. BaillieÁre's Clin Endocrinol Metabolism 1: 551-580.

10. Zeng BJ, Mortimer BC, Martins IJ, Seydel U, Redgrave TG (1988) Chylomicron remnant uptake is regulated by the expression and function of heparan sulfate proteoglycan in hepatocytes. J Lipid Res 39: 845-860.

11. Grundy SM, Mok MYI (1976) Chylomicron clearance in normal and hyperlipoproteinemic subjects. Metabolism 25: 1225-1239.

12. Karpe F, Olivecrona T, Hamsten A, Hultin M (1997) Chylomicron/ chylomicron remnant turnover in humans: evidence for margination of chylomicrons and poor conversion of larger to smaller chylomicron remnants. J Lipid Res 38: 949-961.

13. BjoĖrkegren J, Packard CJ, Hamsten A, Bedford D, Caslake M, et al. (1996) Accumulation of large very low density lipoprotein in plasma during intravenous infusion of a chylomicron-like triglyceride emulsion reflects competition for a common lipolytic pathway. J Lipid Res 37: 76-86.

14. Karpe F, Hultin M (1995) Endogenous triglyceride-rich lipoproteins accumulate in rat plasma when competing with a chylomicron-like triglyceride emulsion for a common lipolytic pathway. J Lipid Res 36 : 1557-1566.

15. Karpe F, HelleÂnius ML, Hamsten A (1999) Differences in postprandial concentrations of very low density lipoprotein and chylomicron remnants between normotriglyceridemic and hypertriglyceridemic men with and without coronary artery disease. Metabolism 48: 301-307.

16. Karpe F (1999) Postprandial lipoportein metabolism and atherosclerosis. J Internal Med 246: 341-355.

17. Semb H, Olivecrona $T$ (1986) Nutritional regulation of lipoprotein lipase in guinea pig tissue. Biochim Biophys Acta 876: 249-255.

18. Ong JM, Kern PA (1989) Effect of feeding and obesity on lipoprotein lipase activity, immunoreactive protein, and messenger RNA levels in human adipose tissue. J Clin Invest 84: 305-311.

19. Frayn KN, Shadid S, Hamlani R, Humphreys SM, Clark ML, et al. (1994) Regulation of fatty acid movement in human adipose tissue in the postabsorbtive-topostprandial transition. Am J Physiol 266: E308-E317.

20. Zilversmit DB (1979) Atherogenesis: a postprandial phenomenon. Circulation 60: 473-485

21. Cohn JS, Marcoux C, Davignon J (1999) Detection, quantification, and characterization of potentially atherogenic triglyceride-rich remnant lipoproteins. Arterioscler Thromb Vasc Biol 19: 2474-2486.

22. Havel RJ, Eder HA, Bragdon JH (1955) The distribution and chemical composition of ultracentrifugally separated lipoproteins in human plasma. J Clin Invest 34: 1345-1353

23. Cohn JS, Johnson EJ, Millar JS, Cohn SD, Milne RW, et al. (1993) Contribution of apoB-48 and apoB-100 triglyceride-rich lipoproteins (TRL) to postprandial increases in the plasma concentration of TRL triglycerides and retinyl esters. J Lipid Res 34: 2033-2040.
24. Rifai N, Merrill JR, Holly RG (1990) Postprandial effect of a high fat meal on plasma lipid, lipoprotein cholesterol and apolipoprotein measurements. Ann Clin Biochem 27: 489-493.

25. Varbo A, Benn M, Tybjærg-Hansen A, Jørgensen AB, Frikke-Schmidt R, et al. (2013) Remnant cholesterol as a causal risk factor for ischemic heart disease. J Am Coll Cardiol 61: 427-436.

26. Nakajima K, Saito T, Tamura A, Suzuki M, Nakano T, et al. (1993) Cholesterol in remnant-like lipoproteins in human serum using monoclonal anti apo B-100 and anti apo A-I immunoaffinity mixed gel. Clin Chim Acta 223: 53-71.

27. Nakajima K, Okazaki M, Tanaka A, Pullinger CR, Wang T, et al. (1996) Separation and determination of remnant-like particles in serum from diabetes patients using monoclonal antibodies to apo B-100 and apo A-I. J Clin Ligand Assay 19: 177-183.

28. Marcoux C, Tremblay M, Nakajima K, Davignon J, Cohn JS (1999) Characterization of remnant-like particles isolated by immunoaffinity gel from the plasma of type III and type IV hyperlipoproteinemic patients. J Lipid Res 40: 636-647.

29. McNamara JR, Shah PK, Nakajima K, Cupples LA, Wilson PW, et al. (2001) Remnant-like particle (RLP) cholesterol is an independent cardiovascular disease risk factor in women: results from the Framingham Heart Study. Atherosclerosis 154: 229-236.

30. Nakajima K, Nakano T, Tanaka A (2006) The oxidative modificationhypothesis of atherosclerosis: the comparison of atherogenic effects on oxidized LDL and remnant lipoproteins in plasma. Clin Chim Acta 367: 36-47.

31. Twickler TB, Dallinga-Thie GM, Cohn JS, Chapman MJ (2004) Elevated remnant-like particle cholesterol concentration: a characteristic feature of the atherogenic lipoprotein phenotype. Circulation 109: 1918-1925.

32. Okazaki M, Usui S, Tada N, Nakano T, Nakajima K (2000) Relation between RLP- triglyceride to RLP-cholesterol ratio and particle size distribution in cholesterol profiles by HPLC. Clin Chim Acta 296: 135-149.

33. Nakajima K, Nakano T, Tokita Y, Nagamine T, Yatsuzuka S, et al. (2012) The characteristics of remnant lipoproteins in the fasting and postprandial plasma. Clin Chim Acta 413: 1077-1086.

34. Nakajima K, Tokita Y, Sakamaki K, Kobayashi J, Kamachi K, et al. (2016) Triglyceride content in remnant lipoproteins is significantly increased after food intake and is associated with plasma lipoprotein lipase. Clin Chim Acta 465: 45-52.

35. Sato K, Okajima F, Miyashita K, Imamura S, Kobayashi J, et al. (2016) Majority of lipoprotein lipase is bound to remnant lipoproteins in plasma: A new definition for remnant lipoproteins. Clin Chim Acta 461: 114-125.

36. Campos E, Nakajima K, Tanaka A, Havel RJ (1992) Properties of an apolipoprotein E-enriched fraction of triglyceride-rich lipoproteins isolated from human blood plasma with a monoclonal antibody to apolipoprotein B-100. J Lipid Res 33: 369-380.

37. Shirakawa T, Nakajima K, Shimomura Y, Kobayashi J, Stanhope K, et al. (2014) Comparison of the effect of post-heparin and pre-heparin lipoprotein lipase and hepatic triglyceride lipase on remnant lipoprotein metabolism. Clin Chim Acta 440: 193-200.

38. Zheng C, Murdoch SJ, Brunzell JD, Sacks FM (2006) Lipoprotein Lipase Bound to Apolipoprotein B Lipoproteins Accelerates Clearance of Postprandial. Lipoproteins in Humans. Arterioscler Thromb Vasc Biol 26: 891-896.

39. Karpe F, Olivecrona T, Walldius G, Hamsten A (1992) Lipoprotein lipase in plasma after an oral fat load: relation to free fatty acids. J Lipid Res 33: 975-984.

40. Goldberg IJ, Kandel JJ, Blum CB, Ginsberg HN (1986) Association of plasma lipoproteins with post-heparin plasma lipase activities. J Clin Invest 78: 1523-1528.

41. Ishiyama N, Sakamaki K, Shimomura Y, Kotani K, Tsuzaki K, et al. Lipoprotein lipase does not increase significantly in the postprandial plasma. Clin Chim Acta 464: 204-210. 
Citation: Nakajima K, Tanaka A (2017) A Proposal of The New Mechanism on Remnant Lipoprotein Formation and Clearance after Food Intake.

Page 8 of 8

42. Buttet M, Poirier H, Traynard V, Gaire K, Trang Tran TT, et al. (2016) Deregulated Lipid Sensing by Intestinal CD36 in Diet-Induced Hyperinsulinemic Obese Mouse Model. PLoS One 11: e0145626.

43. Pérez-Méndez O, Duhal N, Lacroix B, Bonte JP, Fruchart JC, et al. (2006) Different VLDL apo B, and HDL apo AI and apo AII metabolism in two heterozygous carriers of unrelated mutations in the lipoprotein lipase gene. Clin Chim Acta 368: 149-154

44. Beigneux AP, Davies B, Gin P, Weinstein MM, Farber E, et al. (2007) Glycosylphosphatidylinositol-anchored high density lipoprotein-binding protein 1 plays a critical role in the lipolytic processing of chylomicrons. Cell Metab 5: 279-291.

45. Beigneux A, Miyashita K, Ploug M (2017) Autoantibodies against GPIHBP1 as a cause of hypertriglyceridemia. New England J Med.

46. Bergeron N, Havel RJ (1996) Prolonged postprandial responses of lipids and apolipoproteins in triglyceride-rich lipoproteins of individuals expressing an apolipoprotein epsilon 4 allele. J Clin Invest 97: 65-72.

47. Beisiegel U, Weber W, Bengtsson-Olivecrona G (1991) Lipoprotein lipase enhances the binding of chylomicrons to low density lipoprotein receptor-related protein. Proc Natl Acad Sci USA 88: 8342-8346.

48. Nykjaer A, Bengtsson-Olivecrona G, Lookene A, Moestrup SK, Petersen CM, et al. (1993) The alpha 2-macroglobulin/low density lipoprotein receptor-related protein binds lipoprotein lipase and beta-migrating very low density lipoprotein. J Biol Chem 268: 15048-15055.

49. Felts JM, Itakura H, Crane RT (1975) The mechanism of assimilation of constituents of chylomicrons, very low density lipoproteins, and remnants- a new theory. Biochem Biophys Res Commun 66: 1467-1475.

50. Ai M, Tanaka A, Ogita K, Sekinc M, Numano F, et al. (2001) Relationship between plasma insulin concentration and plasma remnant lipoprotein response to an oral fat load in patients with type 2 diabetes. J Am Col Cardiol 38: 1628-1632.

51. Anagnostopoulou KK, Daskalopoulou SS, Mikhailidis DP, Cokkinos DV (2005) Clinical relevance of postprandial lipaemia. Curr Med Chem 12 1931-1945.
52. Tanaka A, Tomie N, Nakano T, Nakajima K, Yui K, et al. (1998) Measurement of postprandial remnant-like particles following a fatloading test. Clin Chim Acta 275: 43-52.

53. Staniak HL, Salgado Filho W, Miname MH, Benseñor IM, Lotufo PA, et al. (2014) Association between postprandial triglycerides and coronary artery disease detected by coronary computed tomography angiography. Atherosclerosis 233: 381-386.

54. Imagawa M, Takahashi S, Zenimaru Y, Kimura T, Suzuki J, et al. (2012) Comparative reactivity of remnant-like lipoprotein particles (RLP) and low-density lipoprotein (LDL) to LDL receptor and VLDL receptor: effect of a high-dose statin on VLDL receptor expression. Clin Chim Acta 413: 441-447.

55. Tomono S, Kawazu S, Kato N, Ono T, Ishii C, et al. (1994) Uptake of remnant like particles (RLP) in diabetic patients from mouse peritoneal macrophages. J Atheroscl Thromb 1: 98-102.

56. Karpe F, Steiner G, Olivecrona T, Carison LA, Hamsten A (1993) Metabolism of triglyceride-rich lipoproteins during alimentary lipemia. J Clin Invest 91: 748-758.

57. Karpe F (1999) Postprandial lipoprotein metabolism and atherosclerosis. J Internal Medicine 246: 341-355.

58. Anagnostopoulou KK, Daskalopoulou SS, Mikhailidis DP, Cokkinos DV (2005) Clinical relevance of postprandial lipaemia. Curr Med Chem 12: 1931-1945.

59. Iso H, Naito Y, Sato S, Kitamura A, Okamura T, et al. (2001) Serum triglycerides and risk of coronary heart disease among Japanese men and women. Am J Epidemiol 153: 490-499.

60. Nordestrgaad BG, Benn M, Schnohr P, Tybjaerg-Hansen A (2007) Nonfasting triglycerides and risk of myocardial infarction, ischemic heart disease, and death in men and women. JAMA 298: 299-308.

61. Bansal S, Buring JE, Rifai N, Mora S, Sacks FM, et al. (2007) Fasting compared with nonfasting triglycerides and risk of cardiovascular events in women. JAMA 298: 309-316. 